\title{
The relative performance of microwave regenerated activated carbons on the removal of phenolic pollutants
}

DOI:

10.1016/j.jclepro.2017.02.188

\section{Document Version}

Accepted author manuscript

Link to publication record in Manchester Research Explorer

\section{Citation for published version (APA):}

Yagmur, E., Turkoglu, S., Banford, A., \& Aktas, Z. (2017). The relative performance of microwave regenerated activated carbons on the removal of phenolic pollutants. Journal of Cleaner Production, 149, 1109-1117. https://doi.org/10.1016/j.jclepro.2017.02.188

\section{Published in:}

Journal of Cleaner Production

\section{Citing this paper}

Please note that where the full-text provided on Manchester Research Explorer is the Author Accepted Manuscript or Proof version this may differ from the final Published version. If citing, it is advised that you check and use the publisher's definitive version.

\section{General rights}

Copyright and moral rights for the publications made accessible in the Research Explorer are retained by the authors and/or other copyright owners and it is a condition of accessing publications that users recognise and abide by the legal requirements associated with these rights.

\section{Takedown policy}

If you believe that this document breaches copyright please refer to the University of Manchester's Takedown Procedures [http://man.ac.uk/04Y6Bo] or contact uml.scholarlycommunications@manchester.ac.uk providing relevant details, so we can investigate your claim.

\section{OPEN ACCESS}




\section{Accepted Manuscript}

The relative performance of microwave regenerated activated carbons on the removal of phenolic pollutants

Emine Yagmur, Songul Turkoglu, Anthony Banford, Zeki Aktas

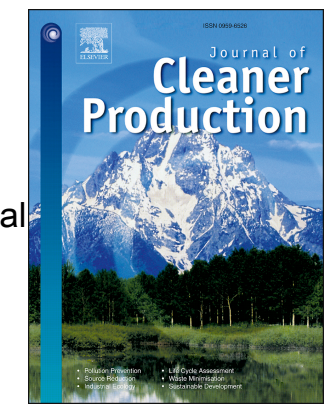

PII:

S0959-6526(17)30414-6

DOI:

10.1016/j.jclepro.2017.02.188

Reference: JCLP 9114

To appear in: Journal of Cleaner Production

Received Date: 30 September 2016

Revised Date: 24 February 2017

Accepted Date: 25 February 2017

Please cite this article as: Yagmur E, Turkoglu S, Banford A, Aktas Z, The relative performance of microwave regenerated activated carbons on the removal of phenolic pollutants, Journal of Cleaner Production (2017), doi: 10.1016/j.jclepro.2017.02.188.

This is a PDF file of an unedited manuscript that has been accepted for publication. As a service to our customers we are providing this early version of the manuscript. The manuscript will undergo copyediting, typesetting, and review of the resulting proof before it is published in its final form. Please note that during the production process errors may be discovered which could affect the content, and all legal disclaimers that apply to the journal pertain. 


\section{Abstract}

The adsorption of reagent on the surface of porous material and the regeneration of porous material are significant processes that are widely used in chemical industries. The performance of a granular commercial activated carbon and two activated carbons synthesised from the factory waste tea and demineralised waste tea, were tested during a series of adsorption and regeneration cycles. Phenol and p-nitrophenol (PNP, 4nitrophenol) were used as the reagents to represent water pollutants. The activated carbon samples were regenerated by the application of a short period of microwave energy (30 s). The influence of the microwave regeneration process on the surface area and pore volumes were investigated with laboratory characterisation techniques. Several cycles of adsorption and regeneration processes were conducted to determine the variation in the adsorption capacity and the characteristics of each porous material. The adsorption and regeneration processes were interpreted in terms of the amount of adsorbed reagent and surface characteristic of the porous material. The materials were found to be good adsorbents for phenol and PNP and the regeneration process worked effectively; broadly maintaining the adsorption capacity over multiple adsorption - regeneration cycles. 


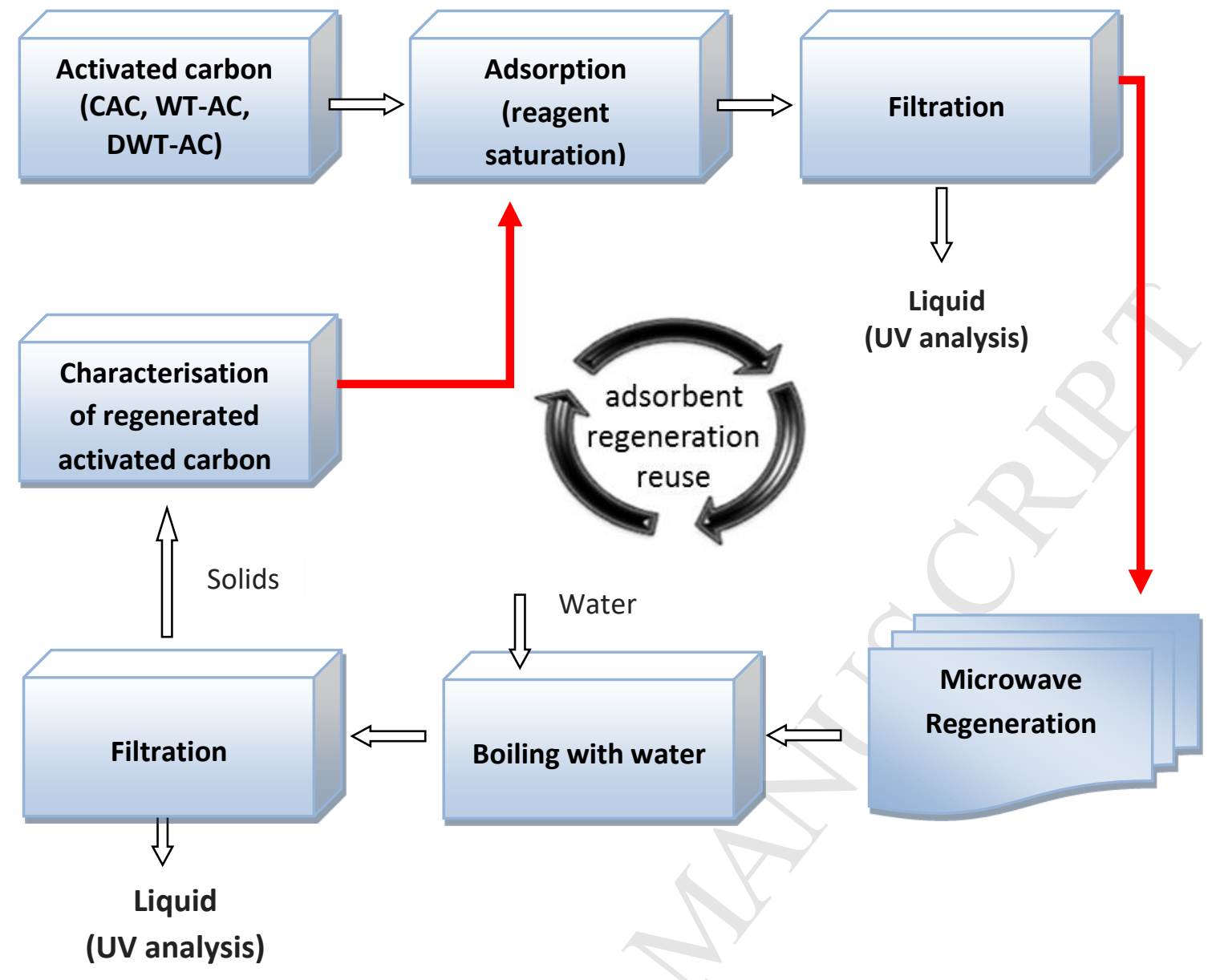




\title{
The Relative Performance of Microwave Regenerated
}

\section{Activated Carbons on the Removal of Phenolic Pollutants}

\author{
Emine Yagmur ${ }^{\mathrm{a}}$, Songul Turkoglu ${ }^{\mathrm{a}}$, Anthony Banford ${ }^{\mathrm{b}}$ and Zeki Aktas ${ }^{\mathrm{a}, \mathrm{b}, 1}$
}

${ }^{a}$ Department of Chemical Engineering, Faculty of Engineering, Ankara University, Tandogan, 06100, Ankara, Turkey.

${ }^{\mathrm{b}}$ School of Chemical Engineering and Analytical Science, The University of Manchester, Sackville Street, Manchester M13 9PL, UK

\begin{abstract}
The adsorption of reagent on the surface of porous material and the regeneration of porous material are significant processes that are widely used in chemical industries. The performance of a granular commercial activated carbon and two activated carbons synthesised from the factory waste tea and demineralised waste tea, were tested during a series of adsorption and regeneration cycles. Phenol and p-nitrophenol (PNP, 4nitrophenol) were used as the reagents to represent water pollutants. The activated carbon samples were regenerated by the application of a short period of microwave energy (30 s). The influence of the microwave regeneration process on the surface area and pore volumes were investigated with laboratory characterisation techniques. Several cycles of adsorption and regeneration processes were conducted to determine the variation in the adsorption capacity and the characteristics of each porous material. The adsorption and regeneration processes were interpreted in terms of the amount of adsorbed reagent and
\end{abstract}

\footnotetext{
${ }^{1}$ Corresponding author. Tel.: +90 312203 3430; fax: +90 3122121546

E-mail address: zaktas@eng.ankara.edu.tr (Zeki Aktas).
} 
surface characteristic of the porous material. The materials were found to be good adsorbents for phenol and PNP and the regeneration process worked effectively; broadly maintaining the adsorption capacity over multiple adsorption - regeneration cycles.

Keywords: Regeneration, Microwave, Activated Carbon, Phenolic pollutant, Adsorption

\section{Introduction}

Porous materials are used in a variety of applications such as separation processes, catalysis, tissue engineering and capacitor manufacture (Gurten et al., 2015). Activated carbon is a porous material that is widely used in many of these and other applications. One specific application is the adsorption of different chemicals on activated carbon. Phenolic compounds are water pollutants due to their toxicity. These compounds are listed as "priority pollutants" by the EPA (Environmental Protection Agency). The removals of phenolic compounds are widely and often used as a test in case studies. Phenolic compounds such as phenol (Salvador and Sanchez Jimenez, 1999), phenol and 4-nitrophenol (Salvador and Sanchez Jimenez, 1996), orto-chlorophenol and pentachlorophenol (Rivera-Utrilla et al., 2003), 2,4,5-trichlorobiphenyl (Liu et al., 2007) have been reported. Dabrowski et al. (2005) published an extensive review detailing phenol and its derivatives used in different concentrations in aqueous media for adsorption onto various activated carbons. Other studies have used a wide range of contaminants to assess the performance of different activated carbons; including promethazine and salicylic acid (Çalışkan et al., 2012), methylene blue (Weng and Hsu, 2008), ethanol and acetone (Fang and Lai, 1996), azo dyes such as Reactive Black 5

(Chang et al., 2010), Direct Red 79 (Salvador and Sanchez Jimenez, 1999) and Acid Orange 7 (Qu et al., 2009). Using these reagents the adsorption capacities, the adsorption 
behaviour and the adsorption kinetics were determined and the related data were also fitted to several models such as Langmuir, Freundlich, Temkin in some of these studies. The activated carbons used in these studies were characterised in terms of by BET surface area, pore size distribution, surface functionality, TG/DTA and SEM analyses.

An activated carbon can be saturated with the reagent during the adsorption process. When the activated carbon reaches its saturation limit, it does not adsorb further reagent. Exhausted activated carbon can be discharged or disposed of in a landfill if it is a low cost material and is within the consent levels. However, activated carbon can be an expensive material and disposal may not be the most sustainable solution. The regeneration of the exhausted material should be considered; to reuse the material and minimise the cost and environmental impact. There are several techniques for regeneration of the exhausted activated carbon such as conventional thermal regeneration (San-Miguel et al., 2001), oxidation (González et al., 2002), solvent regeneration (Chinn and King, 1999), biological regeneration (Scholz and Martin, 1998), electrochemical methods (Narbaitz and Cen, 1994) and ultrasonic regeneration (Hamdaoui et al., 2005). Microwave regeneration has been reported in the literature for activated carbon loaded with different reagents; including 2,4,5-trichlorobiphenyl (Liu et al., 2007), phenol (Ania et al., 2004), salicylic acid (Ania et al., 2007), methylene blue (Foo and Hameed, 2012a) and Acid Orange 7 (Quan et al., 2004).

Microwave irradiation has been widely used domestically, in different fields of industry and also in medical applications. Due to the advantages of microwave irradiation (including safety, speed and selective heating) when compared with conventional heating, microwave heating is an emerging technology in the chemical process industries (Yuen and Hameed, 2009). A number of studies have been reported in the existing literature regarding the use of microwave heating to regenerate activated carbons. Carbons are 
good microwave absorbers due to the interactions of the delocalised $\pi$-electrons with the microwaves. Different types of activated carbons have been employed to adsorb different reagents such as phenolic compounds as reported above. The activated carbons saturated with these reagents were regenerated using microwave heating. The efficiency of regeneration in different successive adsorption and regeneration cycles was reported in these studies. The regenerated samples were characterised in terms of the BET surface area, pore size distribution and surface chemistry.

The main objective of this study was to investigate the effect of sequential microwave regeneration of the saturated activated carbon in equilibrium, in terms of the nature of the regenerated materials and the adsorption performance. The other objective was to determine and contrast the adsorption behaviour of phenol and p-nitrophenol (listed as priority pollutants by the EPA) on powdered activated carbon produced from factory waste tea and on a coal based commercial granulated activated carbon material.

\section{Experimental}

\subsection{Materials}

Commercial activated carbon (CAC) and activated carbon produced from the factory waste tea were used in the adsorption of phenol and p-nitrophenol. Analytical grades of phenol (Riedel de Haen) and PNP (Sigma) were $99.5 \%$ and $99.9 \%$. The waste tea was less than $500 \mu \mathrm{m}$ in particle size. The activated carbon was prepared from the factory waste tea and also a demineralised sample of the factory waste tea. The commercial activated carbon, which was used for comparative purposes, was a coal based porous material and in granule form. 


\subsection{Demineralisation of the waste tea}

The mineral matter in the raw material and in the activated carbon may play a role as a receptor during the microwave heating process (Yagmur et al., 2008a). The surface area and surface properties of the activated carbon may change significantly in the presence of the mineral matter during the microwave regeneration process.

The waste tea sample (20 g) was mixed in a beaker using $200 \mathrm{ml} \mathrm{HCl}(0.1 \mathrm{M})$ solution and the mixture was agitated using a magnetic stirrer at room temperature for 4 hours. The suspension was filtered and washed with distilled water until the filtrate was of neutral $\mathrm{pH}$. The solid was then dried in a vacuum oven for $48 \mathrm{~h}$. This demineralisation method was reported in the literature (Vamvuka et al., 2006).

\subsection{Production of activated carbon}

The production of activated carbon was performed using the natural waste tea (tea factory waste) and demineralised waste tea. The production method previously reported in literature (Yagmur et al., 2008b) was applied. Briefly, the precursor was mixed $\mathrm{H}_{3} \mathrm{PO}_{4}$ (wt, $85 \%$ ) to 2/1 acid/precursor ratio by weight. The material was then exposed to microwave energy (MW) for 30 s (in a domestic type microwave oven: Vestel, MDG-620, $900 \mathrm{~W}$; dimensions (mm): 440x355x259; frequency: $2.45 \mathrm{GHz}$; wavelength: $12.2 \mathrm{~cm}$; quantum energy of microwave photon: $1 \times 10^{-5} \mathrm{eV}$; noise level: $58 \mathrm{~dB}$ ) to enhance the surface area of the final product. The solid mass taken from the microwave oven was carbonised/activated at $450{ }^{\circ} \mathrm{C}$ (heating rate: $10^{\circ} \mathrm{C} / \mathrm{min}$., from room temperature $\left(\approx 20^{\circ} \mathrm{C}\right)$ to $450{ }^{\circ} \mathrm{C}$, takes $\left.43 \mathrm{~min}\right)$ in a quartz tube reactor placed in a temperature programmable rotary tube furnace under $\mathrm{N}_{2}$ flow $(0.15 \mathrm{~L} / \mathrm{min})$. The sample was held in the furnace at $450^{\circ} \mathrm{C}$ for $1 \mathrm{~h}$ before cooling down under a nitrogen flow. The sample was kept in hot distilled water $\left(75^{\circ} \mathrm{C}, 500 \mathrm{ml}\right)$ overnight $(16 \mathrm{~h})$ then washed and 
filtered. The washing process was repeated until the filtrate became neutral. The washed sample was dried in an oven at $110{ }^{\circ} \mathrm{C}$ overnight and then milled at 20,000 rpm for $3 \mathrm{~min}$.

\subsection{Adsorption of phenol and p-nitrophenol (PNP)}

The phenol and PNP adsorption experiments were carried out at $30{ }^{\circ} \mathrm{C}$ in glass vessels. The vessel was covered with a teflon lid to avoid the influence of air during the adsorption process. An orbital shaker (Gerhardt Thermoshaker) was utilised to mix the slurry and the rotation speed of the shaker was $150 \mathrm{rpm}$ during adsorption process. The activated carbon content in the slurry was $2 \% \mathrm{wt} / \mathrm{wt}(9.8 \mathrm{~g}$ solution $+0.2 \mathrm{~g}$ solid). At the end of adsorption process, the sample slurry was withdrawn using a glass syringe and then immediately filtered. A pressure type syringe holder was used to filter the slurry. A high quality polycarbonate membrane filter was employed for the filtration process. The properties of the reagents are reported in Table 1.

\section{[Table 1]}

\subsection{Microwave regeneration}

Prior to microwave regeneration each reagent (at high concentration: 2,000 ppm) was adsorbed on the activated carbon. Phenolic compounds represent a serious potential hazard for human health and aquatic life, and that is why phenols have been registered as a priority pollutant by the US Environmental Protection Agency (USEPA, 1985) with a permissible limit of $0.1 \mathrm{mg} / 1(0.1 \mathrm{ppm})$ in wastewater (Srivastava et al., 2006). The reagent remaining in the water (unadsorbed) was determined using an ultraviolet spectrophotometer (UV). The activated carbon with the adsorbed reagent was regenerated in the same microwave oven used in the production of activated carbon. The regeneration time was $30 \mathrm{~s}$. The temperature reached $530{ }^{\circ} \mathrm{C}$ for the WT-AC (the activated carbon produced from the waste tea) and DWT$\mathrm{AC}$ (the activated carbon produced from the demineralised waste tea) and $585^{\circ} \mathrm{C}$ for the $\mathrm{CAC}$ 
at the end of the irradiation period (30 s). A Raytek IR thermometer was provided to measure the temperature of the regenerated samples. The regenerated sample was mixed with distilled water $(250 \mathrm{ml})$ and boiled for $150 \mathrm{~min}$. The mixture was then filtered and the reagent in the solution was analysed according to the UV technique. The regenerated solid was dried for use in the next adsorption process and for characterisation. Subsequent adsorption tests were carried out as reported above. Fig. 1 shows the adsorption/regeneration processes.

[Fig. 1]

\subsection{Analyses}

The ash content of the waste tea and the demineralised waste tea were determined in accordance with the TAPPI standard method T211 om-85. The contents of $\mathrm{C}, \mathrm{H}, \mathrm{N}$, and $\mathrm{S}$ of the precursors and the adsorbents were measured using a LECO CHNS 932 Elemental Analyser. The oxygen content of the samples was calculated by difference.

A Quantachrome NOVA 2200 series volumetric gas adsorption instrument was employed for specific surface area and pore size analyses. The specific surface areas of the samples (degassed at $140{ }^{\circ} \mathrm{C}$ for $6 \mathrm{~h}$ ) were calculated using multipoint nitrogen adsorption data (between 0.05-0.30, relative pressures) according to the BET method. The pore volumes of the solids were calculated using the Non Local Density Functional Theory (NLDFT) method (Ustinov and Do, 2004). Lately, the method has been widely used for the pore analyses of porous materials (Jagiello and Thommes, 2004). The total pore volume was found from the NLDFT kernel at the relative pressure of 0.99 (Karaman et al., 2014). The micropore volume was determined by interpolation using NLDFT pore size distribution data at $2 \mathrm{~nm}$. The micropore volume was subtracted from the total pore volume to determine the mesopore volume (Gurten et al., 2012).

The concentrations of phenol and PNP remaining in the water were determined using the UV technique (Scinco UV-VIS S-1300 spectrophotometer). To inspect the morphologic 
features of the activated carbon surface, SEM images (magnification: X 50,000) of the samples were obtained by means of an FEI Quanta 400F scanning electron microscope. Prior to the inspection of the sample, the solid particles were coated with a thin layer of gold.

\section{Results and discussion}

\subsection{Characterisation of the solids}

The ash and moisture contents of the waste tea and demineralised waste tea were determined as reported in the analysis section. The ash content of the waste tea was $5.90 \%$ and after the demineralisation process its ash content reduced to $0.58 \%$, this showed that $90.16 \%$ of the mineral matter had been removed from the raw material by this process. The carbon, hydrogen, nitrogen, sulphur and oxygen content of the activated carbons are reported in Table 2. The activated carbons are the commercial activated carbon (CAC), the activated carbon (WT-AC) produced from the waste tea and the activated carbon (DWT-AC) produced from the demineralised waste tea. The hydrogen and nitrogen contents of the activated carbons produced from the raw and demineralised waste tea are substantially higher compared with the commercial activated carbon. The carbon contents of CAC and DWT-AC are very close $(\sim 91 \%)$ and higher than that of the WT-AC.

As reported in the literature, the adsorption process is strongly affected by the presence of heteroatoms such as oxygen, hydrogen or nitrogen. It was also stated in the literature that basic activated carbon with a high nitrogen content presented a higher adsorption capacity for phenolic compounds from liquid solutions (Cansado et al. 2012).

\section{[Table 2]}

The yields were 42.31 and $48.64 \%$ for WT-AC and DWT-AC (Table 3). The BET surface areas of the activated carbons were $1,036,1,153$ and $1,235 \mathrm{~m}^{2} / \mathrm{g}$ for CAC, WT- 
$\mathrm{AC}$ and DWT-AC. The CAC was in granule form whereas the other materials were in powder form.

\section{[Table 3]}

The pore volume data of the activated carbons calculated according to the NLDFT method are tabulated in Table 4. The micro and meso pore volumes are distinctly different when comparing with the commercial activated carbon and the activated carbons produced from the waste tea. As can be seen clearly from the table, the CAC is rich in terms of micropores however the others are rich in mesopores. The micropore volume is 3.73 times higher than mesopore volume for the CAC. For the WT-AC, the mesopore volume is 3.04 times higher than micropore volume. The demineralisation process has naturally affected the pore structure compared with the WT-AC. The process increased the micropore volume; that is, the mesopore volume is 1.6 times higher than micropore volume for the DWT-AC. In the absolute terms, the demineralisation process decreased the mesopore volume from 0.76 $\mathrm{cm}^{3} / \mathrm{g}$ to $0.48 \mathrm{~cm}^{3} / \mathrm{g}$ and increased the micropore volume from $0.25 \mathrm{~cm}^{3} / \mathrm{g}$ to $0.30 \mathrm{~cm}^{3} / \mathrm{g}$.

\section{[Table 4]}

\subsection{SEM Analysis}

The SEM images of the activated carbon are shown in Fig. 2. The images show clearly the differences in surface texture between WT-AC and DWT-AC and the effects of the demineralisation process. It is noticeable that the DWT-AC also has larger voids of a similar scale to the CAC image; yet unlike the nature of the WT-AC.

\section{[Fig. 2]}

\subsection{Adsorption of the reagents}

Phenol Kinetic Experiments: The variation of phenol adsorption with time was determined using the activated carbons; CAC, WT-AC and DWT-AC. The adsorption kinetic data is 
illustrated in Fig. 3. The initial loading concentration of phenol was $400 \mathrm{ppm}$ for the samples. A very fast adsorption takes place in a short time and almost $90 \%$ of the phenol was adsorbed on the surface of WT-AC and DWT-AC. In the use CAC, the adsorption is also fast but not as fast as WT-AC and DWT-AC as can be seen in the figure. The reason for this is the particle size of the CAC (granule form). Fig. 3 clearly shows that the adsorption process reaches equilibrium in a few minutes; the concentration of phenol did not subsequently change up to $96 \mathrm{~h}$ (5,760 min). Similar adsorption kinetic behaviours were reported by Kumar et al. (2007). The adsorption data was fitted to the adsorption kinetic models using Lagergren (1898) pseudo first order, Ho and McKay (1998) pseudo second order, and Elovich (Low, 1960) kinetic equation models. The experimental data fitted well with the data obtained from the pseudo second order model (Fig. 3).

[Fig. 3]

PNP Kinetic Experiments: These adsorption kinetic tests were performed using the CAC and WT-AC. These adsorption kinetic data are reported in Table 5. The WT-AC adsorbed almost all of PNP (> $99 \%)$ in a few minutes, whereas, the CAC adsorbed the same amount of the reagent in almost $1 \mathrm{~h}$. These distinctive rates of adsorption are attributed to the form of the activated carbons used; the forms of CAC and WT-AC were granule and powder, respectively and had different surface areas. As can be easily seen from the table, the diffusion of the reagent into the granule form of the CAC is slower compared with powder WT-AC. Such faster adsorption of PNP was also illustrated in the literature (Kumar et al., 2007).

\section{[Table 5]}

The results of the adsorption kinetic experiments for phenol and PNP clearly show that the adsorption of the reagents are fast processes. As reported in the literature PNP adsorption was faster than that of phenol (Kumar et al., 2007). This was attributed to the different 
chemical structures of phenol and PNP and the surface chemistry of the activated carbons and the type of adsorption, probably due to chemisorption of the reagents (Ania et al., 2002). It has been suggested that phenolic compounds adsorb on the surface of activated carbon via donor-acceptor complex mechanism (Mattson et al., 1969).

\subsection{Phenol Adsorption- Regeneration Cycle Experiments}

These experiments involved repeated cycles of adsorption and regeneration stages as illustrated in Fig.1. The initial reagent concentration of each adsorption stage was 2,000 ppm. When the adsorption process reached equilibrium, the solids were filtered to separate the AC from the filtrate. The quantity of unadsorbed phenol in the filtrate was determined using the UV technique. Figures 4a, 5a and 6a show percent removals of phenol using starting activated carbons (CAC, WT-AC and DWT-AC) and regenerated activated carbons (R1, R2, R3 and R4). The BET surface areas of these activated carbons are presented in Figures $4 b, 5 b$ and $6 b$.

The CAC: Fig. $4(\mathrm{a}, \mathrm{b})$ shows the removal of phenol adsorbed on the surface and the surface area of the CAC and regenerated CACs. As removal of the phenol was $76.2 \%$ for the starting CAC, the removals sharply increased to $98.5 \%$ after the regeneration processes. It was still higher (93.3\%) even (fourth regeneration) for R4. The BET surface areas of the CAC and the regenerated CACs are shown in Fig. 4b. The surface area slightly increased to $1,109 \mathrm{~m}^{2} / \mathrm{g}$ after the first regeneration. The surface area values gradually decreased in the following regeneration stages. These results are consistent with the studies performed by Ania et al. (2007), and Çalışkan et al. (2012), who reported that the surface area decreased slightly during the first regeneration cycle.

[Fig. 4] 
It is worth reporting the increase in phenol removal and the gradual decrease in the BET surface area. Although the gradual decreases in the surface areas (except for R1) are determined, the removals are significantly higher compared with the starting CAC. This clearly indicates that the regeneration process significantly enhances the adsorption ability of the solid surfaces.

Ania et al. (2004) showed that MW regeneration was more efficient than conventional heating methods. They focused on textural changes after the regeneration process. They concluded that conventional regeneration caused deposits on the surface of the pore walls; deposits would be lower with MW regeneration.

The surface area of the regenerated samples gradually decreased as presented in related figures. Similar trends were reported by Ania et al. (2004), who showed that the adsorption capacity of the regenerated activated carbons decreased with regeneration cycles. This study found that there were no significant changes in the performance of WT-AC and DWT-AC following regeneration, whereas the performance of CAC improved.

The reason for the higher removals should be explained for the regeneration cycles. The solid surface contains phenol molecules at the end of adsorption process. The adsorbed phenol molecules may significantly alter the functionality of the solid surface due to surface reaction/chemisorption during microwave irradiation (Dabrowski et al., 2005). Therefore the altered surface enhanced the adsorption of phenol molecules as a result of the different functional groups.

In fact the pore volume data reported in Table 6 are also important to explain the reason why the adsorption capacity changed. The meso and micro pore volumes of the starting CAC (not regenerated) were 0.112 and $0.412 \mathrm{~cm}^{3} / \mathrm{g}$. The mesopore volume increased significantly from 0.112 to $0.229 \mathrm{~cm}^{3} / \mathrm{g}$, after the first regeneration. However, the micropore volume dropped from 0.412 to $0.364 \mathrm{~cm}^{3} / \mathrm{g}$. This decrease in the micropore volume may 
indicate that some micropores merged to form mesopores thereby increasing the mesopore volume during the first regeneration. However, during subsequent regenerations, both the mesopore and micropore volumes progressively decreased. This is consistent with the BET surface area observations.

\section{[Table 6]}

The increase in the mesopore volume is significant for the adsorption and adsorption kinetics. The accessible pore volume plays a very important role in the adsorption process, depending on the adsorbate size and the chemical structure. Mesopores are wider than the micropores and the micropores, so diffusion of the reagent into the mesopores is faster than into the micropores. This directly affects the adsorption rate and the amount of reagent adsorbed. The amount of phenol adsorbed increased and the removal of the reagent was higher for the regenerated samples compared with the starting CAC. This high removal is not only due to an increase in mesopore volume but also due to surface properties of solids (Dabrowski et al., 2005).

The WT-AC: The phenol removal process was different for the WT-AC compared with the CAC (Fig. $5(\mathrm{a}, \mathrm{b})$ ). The first regeneration improved the removal of phenol from $73.35 \%$ to $81.44 \%$. There is no significant difference for the second and the following regeneration stages, although the surface area gradually decreases. This is again attributed to the reactions/chemisorption occurring during the regeneration stage in the course of microwave irradiation. Simply, the surface functionality was changed by an adsorbed layer of phenol as reported in CAC. However, the values of the removals are not that high as noted for CAC. This may be due to the different origins and surface functionality of the CAC and WT-AC. This explanation agrees with the results reported by Ania et al. (2002) who used different types of commercial activated carbons.

[Fig. 5] 
The surface area data of the WT-AC and the regenerated WT-ACs are illustrated in Fig. $5 \mathrm{~b}$. The surface area of the regenerated samples is lower than that of the WT-AC and broadly decreased with the regeneration cycles. The surface area of the original WT-AC was $1,153 \mathrm{~m}^{2} / \mathrm{g}$, whereas the surface area after five cycles was $920 \mathrm{~m}^{2} / \mathrm{g}$. This represents a loss of the surface area of around $20 \%$ compared with the starting WT-AC.

The pore volumes of these samples are tabulated in Table 7. The total pore volume tends to decrease as do both the meso and micropore volumes with the regeneration cycles. The pore fractions simply show that as the mesopore fraction increases and the micropore fraction slowly decreases during the cycles. Removals also reduced with consecutive regeneration steps except for the first regeneration $(\mathrm{R} 1)$. The regeneration process is fundamentally a heat treatment process and may cause changes in the surface properties and also deposits on the pore walls as result of decomposition of (physically and chemically) absorbed reagents (Ania et al., 2007).

\section{[Table 7]}

The DWT-AC: The percentage removals and the surface areas are shown in Fig. 6 (a, b) for the DWT-AC experiments. The amount of phenol removed improved slightly with the regenerated samples. As phenol removal is $72.4 \%$ for the starting DWT-AC, it is $77.9 \%$ for the sample obtained at the end of fourth regeneration (R4). This slight increase in the removal may be attributed to both the interaction between the solid surface and the phenol molecules adsorbed on the surface during the regeneration process and also the demineralisation process. It is reported once more that the use of microwave energy for regeneration improves the adsorption of phenol, and therefore increases the removal of the undesired phenol on the surface.

[Fig 6.] 
Fig. $6 \mathrm{~b}$ shows variation of the BET surface area of the DWT-AC and its regenerated samples with the regeneration stages. Similar trends are seen for the DWT-AC, to those for WT-AC (Fig. 5b); the surface area steadily decreased from 1,082 to $891 \mathrm{~m}^{2} / \mathrm{g}$ during the regeneration processes for DWT-AC. The pore volumes are given in Table 8 and as expected the values steadily decreased. In general, the surface area decreased with the regeneration process for the activated carbons, however the amount of phenol adsorbed increased on the solid surface for some experiments.

\section{[Table 8]}

The regeneration process obviously shows that the textural structure has been changed as well as the surface properties of the solid particles. Changes in the pore volumes and the surface area are results of the collapse of some pores and the merging of pores. Although the surface area decreased gradually, the amount of reagent adsorbed increased slightly. There are potentially several reasons; firstly the surface functionality may have changed, secondly demineralisation may affect the surface properties and finally the removal of volatile matter due to MW energy could create active sites for chemisorption (Ania et al., 2005).

It is clear that the regeneration process is having a more marked effect on the surface properties of the CAC than WT-AC and DWT-AC; notably on the BET surface area and on the mesopore volumes. Whilst the regeneration is broadly maintaining the adsorption performance of the WT-AC and DWT-AC, it is also significantly increasing the adsorption capacity of the CAC over the course of 5 cycles.

The structural variations in the activated carbon are due to microwave irradiation during the regeneration process. However, it should be reported that the microwave heating process strongly depends on several factors such as the nature of material being heated and the application method of microwave irradiation. It is known that the microwave process activates dipole molecules depending upon their dielectric constants (dielectric heating); therefore, sample composition and location relative to the flux could impact on the structure 
of the product. This may affect the regeneration processes and the porosity of the regenerated activated carbon could also be affected (Yagmur et al., 2013). Another possible factor is the mineral contents of the activated carbon, which does affect the microwave heating process. As is widely reported in the literature, the presence of mineral matter (inorganic matter) such as metal oxides, carbonates, nitrates, silicates is significant in MW heating and where they may behave as a receptor (Monsef-Mirzai et al., 1992). The dielectric properties of a receptor are critical to the maximum temperature. Therefore the regeneration of activated carbon containing mineral matter may strongly be influenced by the receptor properties of the mineral matter. Consequently, temperature gradients will exist in solid samples and potentially change its surface properties.

In general the results are consistent with several studies reported in the literature (Ania et al., 2007) where the surface area, the micro and the mesopore volumes gradually decreased. However, the results are inconsistent with the findings given by Liu et al. (2004). Foo and Hameed (2012b) reported that the surface area increased after seven regeneration cycle and the regenerated carbon did not differ noticeably from the parent carbon.

\subsection{PNP Adsorption- Regeneration Cycle Experiments}

The results of the PNP adsorption and regeneration experiments with CAC are detailed for the three regeneration cycles. Fig. $7(a, b)$ shows the removal of PNP and the surface areas of the CAC and regenerated CACs. The original CAC adsorbed $99 \%$ of the initial loading of PNP. The removals are even better for the samples after the regeneration processes. This suggests that the regeneration with MW energy improves the adsorption capacity of this activated carbon (CAC).

[Fig.7] 
Indeed as can be seen in Fig. 7b, the regeneration process increased the surface area when compared with the starting CAC. The increase in the surface area was almost $14 \%$ after the first regeneration. The surface areas were 1,099 and 1,079 $\mathrm{m}^{2} / \mathrm{g}$ for the second and third regeneration processes. If these results are compared with those of the experiments performed with phenol, the surface area values are different; the surface area remains greater following regeneration in the case of PNP. This may be attributed to the phenol or PNP that has adsorbed on the surface of the activated carbon; the reagents may chemically (due to reaction or chemisorption) affect the surface during the regeneration process differently (Vidic et al., 1997).

The pore volume data are tabulated in Table 9 . The mesopore volume generally increased with the regeneration process with the exception of the second cycle.

\section{[Table 9]}

\section{Conclusions}

Microwave irradiation for a short period (30 s) is an effective technique to regenerate the activated carbons loaded with adsorbed phenol or PNP. Although the surface area and pore volume are changed during the regeneration process, the amount of adsorbed reagent was broadly maintained following successive regenerations; indeed enhanced adsorption occurred in some cases. Notably for the adsorption of phenol onto CAC the increase in mesopore volume after the first regeneration significantly improved the adsorption.

When the adsorption of the reagents used and the properties of the regenerated carbon samples are considered, the activated carbons produced from the waste tea and demineralised waste tea are good porous materials for the adsorption of phenol and PNP. The regeneration process was effective and facilitates the reuse of these materials and improved sustainability. 
The demineralisation process changed the elemental composition and textural characteristics of the final WT product. As the surface area and the micropore volume of the DWT-AC were higher than that of the WT-AC, the mesopore volume of the DWT-AC is $0.48 \mathrm{~cm}^{3} / \mathrm{g}$ which is lower than the mesopore volume of the WT-AC $\left(0.76 \mathrm{~cm}^{3} / \mathrm{g}\right)$.

Phenol adsorption was initially fast with the majority of the reagent adsorbed on the activated carbons in a short time, before reaching equilibrium thereafter. Similar adsorption behaviour was observed with PNP.

\section{Acknowledgement}

The authors gratefully acknowledge the Scientific and Technological Research Council of Turkey (TUBITAK) for provision of equipment and facilities for previous projects (Project numbers: 107M306 and 109M400). The corresponding author would also like to acknowledge the University of Manchester for use of their facilities during his sabbatical year in the UK. 


\section{References}

Ania, C.O., Menendez, J.A., Parra, J.B., Pis, J.J., 2004. Microwave-induced regeneration of activated carbons polluted with phenol. A comparison with conventional thermal regeneration. Carbon. 42, 1383-1387.

Ania, C.O., Parra, J.B., Mene'ndez, J.A., Pis, J.J., 2005. Effect of microwave and conventional regeneration on the microporous and mesoporous network and on the adsorptive capacity of activated carbons. Micropor. Mesopor. Mat. 85, 7-15.

Ania, C.O., Parra, J.B., Menendez, J.A., Pis, J.J., 2007. Microwave-assisted regeneration of activated carbons loaded with pharmaceuticals. Water Res. 41, 3299-3306.

Ania, C.O., Parra, J.B., Pis, J.J., 2002. Effect of texture and surface chemistry on adsorptive capacities of activated carbons for phenolic compounds removal. Fuel Process.Technol. 7778, 337-343.

Çalışkan, E., Bermúdez, J.M., Parra, J.B., Menéndez, J.A., Mahramanlioglu, M., Ania, C.O., 2012. Low temperature regeneration of activated carbons using microwaves: Revising conventional wisdom. J. Environ. Manage. 102, 134-140.

Cansado, I. P., Mourão, P. A., Falcão, A. I., Carrott, M. R., \& Carrott, P. J. 2012. The influence of the activated carbon post-treatment on the phenolic compounds removal. Fuel processing technology, 103, 64-70.

Chang, S.H., Wang, K.S., Liang, H.H., Chen, H.Y., Li, H.C., Peng, T.H., Su, Y.C., Chang, C.Y., 2010. Treatment of Reactive Black 5 by combined electrocoagulation-granular activated carbon adsorption-microwave regeneration process. J. Hazard. Mater. 175, 850857.

Chinn, D., King, C.J., 1999. Adsorption of glycols, sugar, and related multiple-OH compounds onto activated carbons. 2. Solvent regeneration. Ind. Eng. Chem. Res. 38, 37463753.

Dabrowski, A., Podkoscielny, P., Hubicki, Z., Barczak, M., 2005. Adsorption of phenolic compounds by activated carbon-a critical review. Chemosphere. 58, 1049-1070.

Fang, C.S., Lai, P.M.C., 1996. Microwave regeneration of spent powder activated carbon. Chem. Eng. Comm. 147, 17-27.

Foo, K.Y., Hameed, B.H., 2012a. A rapid regeneration of methylene blue dye-loaded activated carbons with microwave heating. J. Anal. Appl. Pyrols. 98, 123-128.

Foo, K.Y., Hameed, B.H., 2012b. A cost effective method for regeneration of durian shell and jackfruit peel activated carbons by microwave irradiation. Chem. Eng. J. 193-194, 404-409. 
González, J.F., Encinar, J.M., Ramiro, A., Sabio, E., 2002. Regeneration by wet oxidation of an activated carbon saturated with p-nitrophenol. Ind. Eng. Chem. Res. 41, 1344-1351.

Gurten Inal I.I, Holmes S., Banford A., Aktas Z., 2015. The performance of supercapacitor electrodes developed from chemically activated carbon produced from waste tea. Applied Surface Science. 357, 696-703.

Gurten, I.I., Ozmak, M., Yagmur, E., Aktas, Z., 2012. Preparation and characterisation of activated carbon from waste tea using $\mathrm{K}_{2} \mathrm{CO}_{3}$. Biomass Bioenerg. 37, 73-81.

Hamdaoui, O., Naffrechoux, E., Suptil, J., Fachinger, C., 2005. Ultrasonic desorption of pchlorophenol from granular activated carbon. Chem. Eng. J. 106, 153-161.

Ho, Y.S., McKay, G., 1998. A comparison of chemisorption kinetic models applied to pollutant removal on various sorbents. Process Safety and Environmental Protection, 76(4), 332-340.

Jagiello, J., Thommes, M., 2004. Comparison of DFT characterization methods based on $\mathrm{N}_{2}$, Ar, $\mathrm{CO}_{2}$ and $\mathrm{H}_{2}$ adsorption applied to carbons with various pore size distributions. Carbon. $42,1227-1232$.

Karaman, I., Yagmur, E., Banford, A., Aktas, Z., 2014. The effect of process parameters on the carbon dioxide based production of activated carbon from lignite in a rotary reactor. Fuel Process. Technol. 118, 34-41.

Kumar, A., Kumar, S., Kumar, S., Gupta, D.V., 2007. Adsorption of phenol and 4nitrophenol on granular activated carbon in basal salt medium: Equilibrium and kinetics. J. Hazard. Mater. 147, 155-166.

Lagergren, S., 1898. About the theory of so-called adsorption of soluble substances, Kungliga Svenska Vetenskapsakademiens. Handlingar, 24 (4), 1-39.

Liu, X., Quan, X., Bo, L., Chen, S., Zhao, Y., 2004. Simultaneous pentachlorophenol decomposition and granular activated carbon regeneration assisted by microwave irradiation. Carbon. 42, 415-422.

Liu, X., Yu, G., Han, W., 2007. Granular activated carbon adsorption and microwave regeneration for the treatment of 2,4,5-trichlorobiphenyl in simulated soil-washing solution. J. Hazard. Mater. 147, 746-751.

Low, M. J. D., 1960, Kinetics of chemisorption of gases on solids, Chemical Reviews, 60, 267-312.

Mattson, J.S., Mark, J.H.B., Malbin, M.D., Weber, J.W.J., 1969. Crittenden JC. Surface chemistry of active carbon: Specific adsorption of phenols. J. Colloid. Interf. Sci. 31, 116130. 
Monsef-Mirzai, P.; Ravidran, M.; McWhinnie, M. R.; Burchill, P. 1992. The use of microwave heating for the pyrolysis of coal via inorganic receptors of microwave energy Fuel, 71, 716-717.

Narbaitz, R.M., Cen, J., 1994. Electrochemical regeneration of granular activated carbon. Water Res. 28, 1771-1778.

Qu, G.Z., Li, J., Wu, Y., Li, G.F., Li, D., 2009. Regeneration of acid orange 7-exhausted granular activated carbon with dielectric barrier discharge plasma. Chem. Eng. J. 146, 168173.

Quan, X., Liu, X.T., Bo, L.L., Chen, S., Zhao, Y.Z., Cui, X.Y., 2004. Regeneration of acid orange 7-exhausted columned granular activated carbons with microwave irradiation. Water Res. 38, 4484-4490.

Rivera-Utrilla, J., Ferro-Garcia, M.A., Bautista-Toledo, I., Sanchez-Jimenez, C., Salvador, F., Merchan, M.D., 2003. Regeneration of ortho-chlorophenol-exhausted activated carbons with liquid water at high pressure and temperature. Water Res. 37, 1905-1911.

Salvador, F., Sanchez Jimenez, C., 1996. A new method for regenerating activated carbon by thermal desorption with liquid water under subcritical conditions. Carbon. 34, 511-516.

Salvador, F., Sanchez Jimenez, C., 1999. Effect of regeneration treatment with liquid water at high pressure and temperature on the characteristics of three commercial activated carbon. Carbon. 37, 577-583.

San-Miguel, G., Lambert, S.D., Graham, N.J.D., 2001. The regeneration of field-spent granular-activated carbons. Water Res. 35, 2740-2748.

Scholz, M., Martin, R.J., 1998. Control of bio-regenerated columned granular activated carbon by spreadsheet modelling. J. Chem. Technol. Biot. 71, 253-261.

Srivastava, V.C., Swamy, M.S., Mall, I.D., Prasad, B., Mishra, I.M., 2006. Adsorptive removal of phenol by bagasse fly ash and activated carbon: equilibrium, kinetics and thermodynamics. Colloid Surf. A. 272, 89-104.

United States Enviromental Protection Agency (USEPA). 1985. Technical support document for water quality based toxics control. EPA/440/485032. USEPA, Washington, DC.

Ustinov, E.A., Do, D.D., 2004. Application of density functional theory to analysis of energetic heterogeneity and pore size distribution of activated carbons. Langmuir. 20, 37913797.

Vamvuka, D., Troulinos, S., Kastanaki, E., 2006. The effect of mineral matter on the physical and hemical activation of low rank coal and biomass materials. Fuel. 85, 1763-1771. 
Vidic, R. D., Tessmer, C. H., \& Uranowski, L. J. 1997. Impact of surface properties of activated carbons on oxidative coupling of phenolic compounds. Carbon, 35(9), 1349-1359.

Weng, C.H., Hsu, M.C., 2008. Regeneration of granular activated carbon by an electrochemical process. Sep. Purif. Technol. 64, 227-236.

Yagmur, E., Simsek, E. H., Aktas, Z., Togrul, T. 2008a. Effect of CuO receptor on the liquid yield and composition of oils derived from liquefaction of coals by microwave energy. Energy Conversion and Management, 49(11), 3043-3050.

Yagmur, E., Ozmak, M., Aktas, Z., 2008b. A novel method for production of activated carbon from waste tea by chemical activation with microwave energy. Fuel. 87, 3278-3285.

Yagmur, E., Tunc, M.S., Banford, A., Aktas, Z., 2013. Preparation of activated carbon from autohydrolysed mixed southernhardwood. J. Anal. Appl. Pyrols. 104, 470-478.

Yuen, F.K., Hameed, B.H., 2009. Recent developments in the preparation and regeneration of activated carbons by microwaves. Adv. Colloid. Interfac. 149, 19-27. 


\section{Figure captions}

Fig. 1 The adsorption/regeneration process - adsorbent reuse

Fig. 2 SEM images of the activated carbons (X50,000)

Fig. 3 Adsorption time versus phenol remaining in water

Fig. 4 Phenol removal (a) and the BET surface area (b) versus the CAC and regenerated CACs

Fig. 5 Phenol removal (a) and the BET surface area (b) versus the WT-AC and regenerated WT-ACs

Fig. 6 Phenol removal (a) and the BET surface area (b) versus the DWT-AC and regenerated DWT-ACs

Fig.7 PNP removal (a) and the BET surface area (b) versus the CAC and regenerated CACs 
Table 1

Properties of phenol and PNP

Phenol PNP (4-nitrophenol)

\begin{tabular}{lcc}
\hline Molecular formula & $\mathrm{C}_{6} \mathrm{H}_{5} \mathrm{OH}$ & $\mathrm{C}_{6} \mathrm{H}_{5} \mathrm{NO}_{3}$ \\
Molar mass, g/mol & 94.11 & 139.11 \\
Density, g/cm & 1.07 & 1.27 \\
Melting point, ${ }^{\circ} \mathrm{C}$ & 1.07 & $113-114$ \\
Boiling point, ${ }^{\circ} \mathrm{C}$ & 40.50 & 279 \\
Solubility in water $\left(20{ }^{\circ} \mathrm{C}\right)$ & 181.70 & $11.6 \mathrm{~g} / \mathrm{L}$ \\
\hline
\end{tabular}


Table 2

Elemental compositions of the activated carbons

\begin{tabular}{lccccc}
\hline & \multicolumn{5}{c}{ Elemental analysis (\%), daf } \\
\cline { 2 - 6 } & $\mathbf{C}$ & $\mathbf{H}$ & $\mathbf{N}$ & $\mathbf{S}$ & $\mathbf{O}^{\mathbf{b}}$ \\
\hline CAC & 90.95 & 0.93 & 0.32 & 0.04 & 7.76 \\
WT-AC & 84.17 & 2.44 & 0.98 & 0.08 & 12.33 \\
DWT-AC & 91.06 & 3.15 & 1.42 & 0.03 & 4.34
\end{tabular}

${ }^{\mathrm{a}}$ dry ash free basis

${ }^{\mathrm{b}}$ calculated by difference 
Table 3

The activated carbons used in the adsorption/regeneration experiments.

\begin{tabular}{lccc}
\hline Form & $\begin{array}{c}\text { BET surface area } \\
\left(\mathbf{m}^{\mathbf{2}} / \mathbf{g}\right)\end{array}$ & $\begin{array}{c}\text { Yield (dry basis) } \\
(\mathbf{w t} . \%)\end{array}$ \\
\hline CAC & Granule & 1,036 & - \\
WT-AC & Powder & 1,153 & 42.31 \\
DWT-AC & Powder & 1,235 & 48.64 \\
\hline
\end{tabular}


Table 4

Pore volume data of the activated carbons

\begin{tabular}{lccccc}
\hline & \multicolumn{3}{c}{ Pore volume, $\left(\mathrm{cm}^{3} / \mathbf{g}\right)$} & \multicolumn{2}{c}{ Pore fraction, (\%) } \\
\hline & Total & Meso & Micro & Meso & Micro \\
CAC & 0.52 & 0.11 & 0.41 & 21.15 & 78.85 \\
WT-AC & 1.00 & 0.76 & 0.25 & 76.00 & 25.00 \\
DWT-AC & 0.78 & 0.48 & 0.30 & 61.54 & 38.46 \\
\hline
\end{tabular}


Table 5

Kinetic data for the adsorption of PNP on the CAC and WT-AC

\begin{tabular}{cccc}
\hline \multicolumn{2}{c}{ CAC } & \multicolumn{2}{c}{ WT-AC } \\
\hline $\begin{array}{c}\text { Time } \\
(\mathrm{min})\end{array}$ & $\begin{array}{c}\text { PNP in water } \\
(\mathrm{ppm})\end{array}$ & $\begin{array}{c}\text { Time } \\
(\mathrm{min})\end{array}$ & $\begin{array}{c}\text { PNP in water } \\
(\mathrm{ppm})\end{array}$ \\
\hline 0.0 & 400.0 & 0.0 & 400.0 \\
0.5 & 238.8 & 2.0 & 1.2 \\
2.0 & 92.5 & 5.0 & 0.9 \\
5.0 & 12.0 & 10.0 & 0.8 \\
15.0 & 3.8 & 30.0 & 0.6 \\
30.0 & 1.9 & 60.0 & 0.1 \\
45.0 & 1.7 & - & - \\
60.0 & 2.0 & - & - \\
180.0 & 1.7 & - & - \\
300.0 & 1.4 & - & - \\
390.0 & 1.7 & - & - \\
$1,440.0$ & 2.1 & - & - \\
$1,710.0$ & 1.9 & - & - \\
$2,880.0$ & 1.6 & - & - \\
$2,940.0$ & 1.9 & - & - \\
\hline
\end{tabular}


Table 6

Pore volume data for the CAC and regenerated CACs (Phenol)

\begin{tabular}{llllll}
\hline & \multicolumn{3}{c}{ Pore volume, $\left(\mathbf{c m}^{\mathbf{3}} / \mathbf{g}\right)$} & \multicolumn{2}{c}{ Pore fraction, (\%) } \\
\cline { 2 - 6 } & Total & Meso & Micro & Meso & Micro \\
\hline CAC & 0.524 & 0.112 & 0.412 & 21.37 & 78.63 \\
R1 & 0.593 & 0.229 & 0.364 & 38.62 & 61.38 \\
R2 & 0.543 & 0.205 & 0.338 & 37.75 & 62.25 \\
R3 & 0.474 & 0.176 & 0.298 & 37.13 & 62.87 \\
R4 & 0.387 & 0.151 & 0.236 & 39.02 & 60.98 \\
R5 & 0.355 & 0.150 & 0.205 & 42.25 & 57.75 \\
\hline
\end{tabular}


Table 7

Pore volume data for the WT-AC and regenerated WT-ACs (Phenol)

\begin{tabular}{lccccc}
\hline & \multicolumn{2}{c}{ Pore volume, $\left(\mathrm{cm}^{\mathbf{3}} / \mathbf{g}\right)$} & \multicolumn{2}{c}{ Pore fraction, (\%) } \\
& Total & Meso & Micro & Meso & Micro \\
\hline WT-AC & 1.004 & 0.758 & 0.246 & 75.50 & 24.50 \\
R1 & 0.859 & 0.628 & 0.231 & 73.11 & 26.89 \\
R2 & 0.844 & 0.650 & 0.194 & 77.01 & 22.99 \\
R3 & 0.888 & 0.689 & 0.199 & 77.59 & 22.41 \\
R4 & 0.870 & 0.675 & 0.195 & 77.59 & 22.41 \\
R5 & 0.847 & 0.669 & 0.178 & 78.98 & 21.02 \\
\hline
\end{tabular}


Table 8

Pore volume data for the DWT-AC and regenerated DWT-ACs (Phenol)

\begin{tabular}{lccccc}
\hline & \multicolumn{3}{c}{ Pore volume, $\left(\mathbf{c m}^{\mathbf{3}} / \mathbf{g}\right)$} & \multicolumn{2}{c}{ Pore fraction, (\%) } \\
\cline { 2 - 6 } & Total & Meso & Micro & Meso & Micro \\
\hline DWT-AC & 0.777 & 0.477 & 0.300 & 61.39 & 38.61 \\
R2 & 0.676 & 0.416 & 0.260 & 61.54 & 38.46 \\
R3 & 0.643 & 0.406 & 0.237 & 63.14 & 36.86 \\
R4 & 0.588 & 0.386 & 0.202 & 65.65 & 34.35 \\
R5 & 0.591 & 0.385 & 0.206 & 65.14 & 34.86 \\
& 0.573 & 0.371 & 0.202 & 64.75 & 35.25 \\
\hline
\end{tabular}


Table 9

Pore volume data for the $\mathrm{CAC}$ and regenerated CACs (PNP)

\begin{tabular}{llllll}
\hline & \multicolumn{3}{c}{ Pore volume, $\left(\mathbf{c m}^{\mathbf{3}} / \mathbf{g}\right)$} & \multicolumn{2}{c}{ Pore fraction, (\%) } \\
\cline { 2 - 6 } & Total & Meso & Micro & Meso & Micro \\
\hline CAC & 0.524 & 0.112 & 0.412 & 21.37 & 78.63 \\
R1 & 0.630 & 0.236 & 0.394 & 37.46 & 62.54 \\
R2 & 0.535 & 0.098 & 0.437 & 18.32 & 81.68 \\
R3 & 0.573 & 0.208 & 0.365 & 36.30 & 63.70 \\
\hline
\end{tabular}




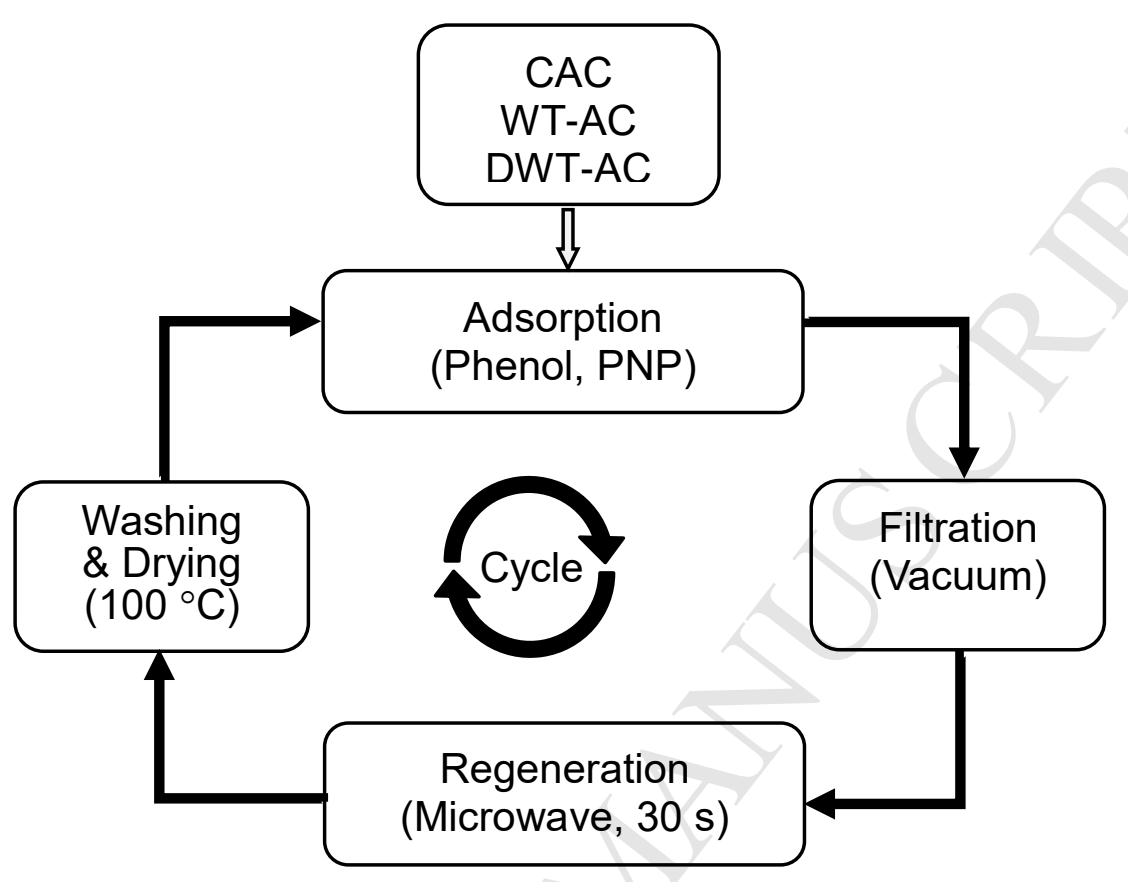

Fig. 1 


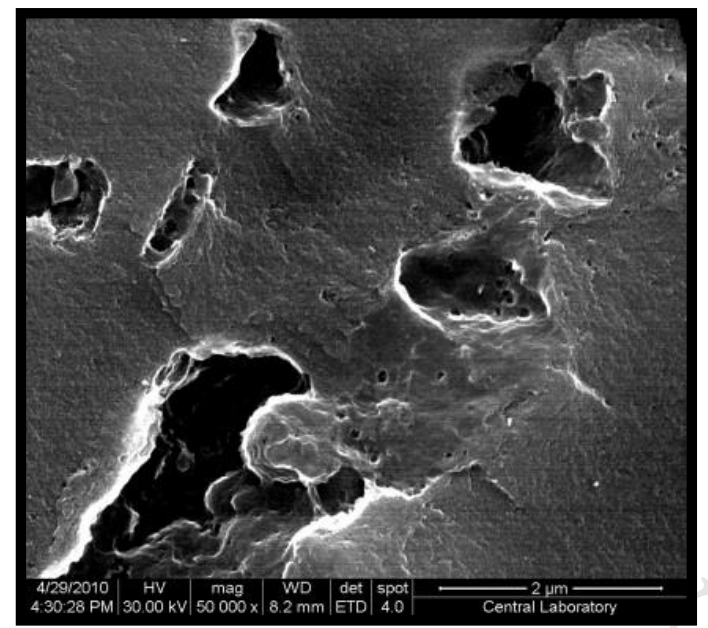

CAC

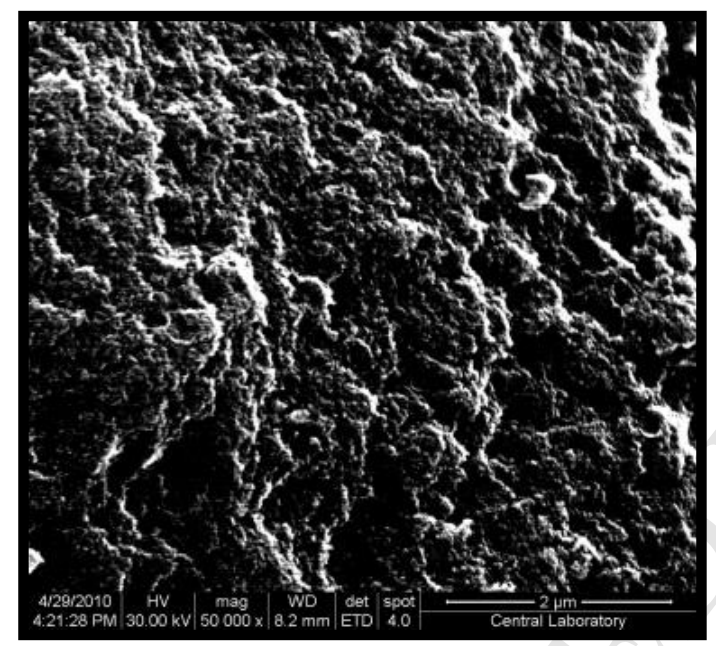

WT-AC

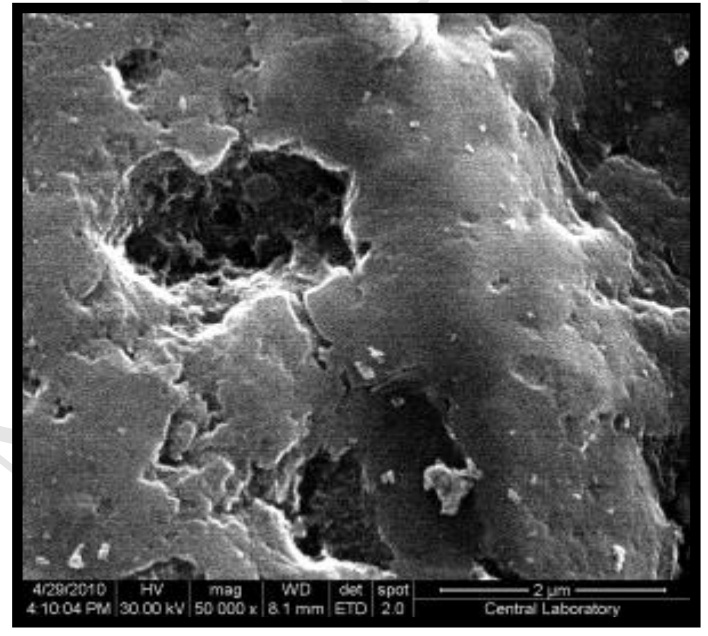

DWT-AC

Fig. 2 


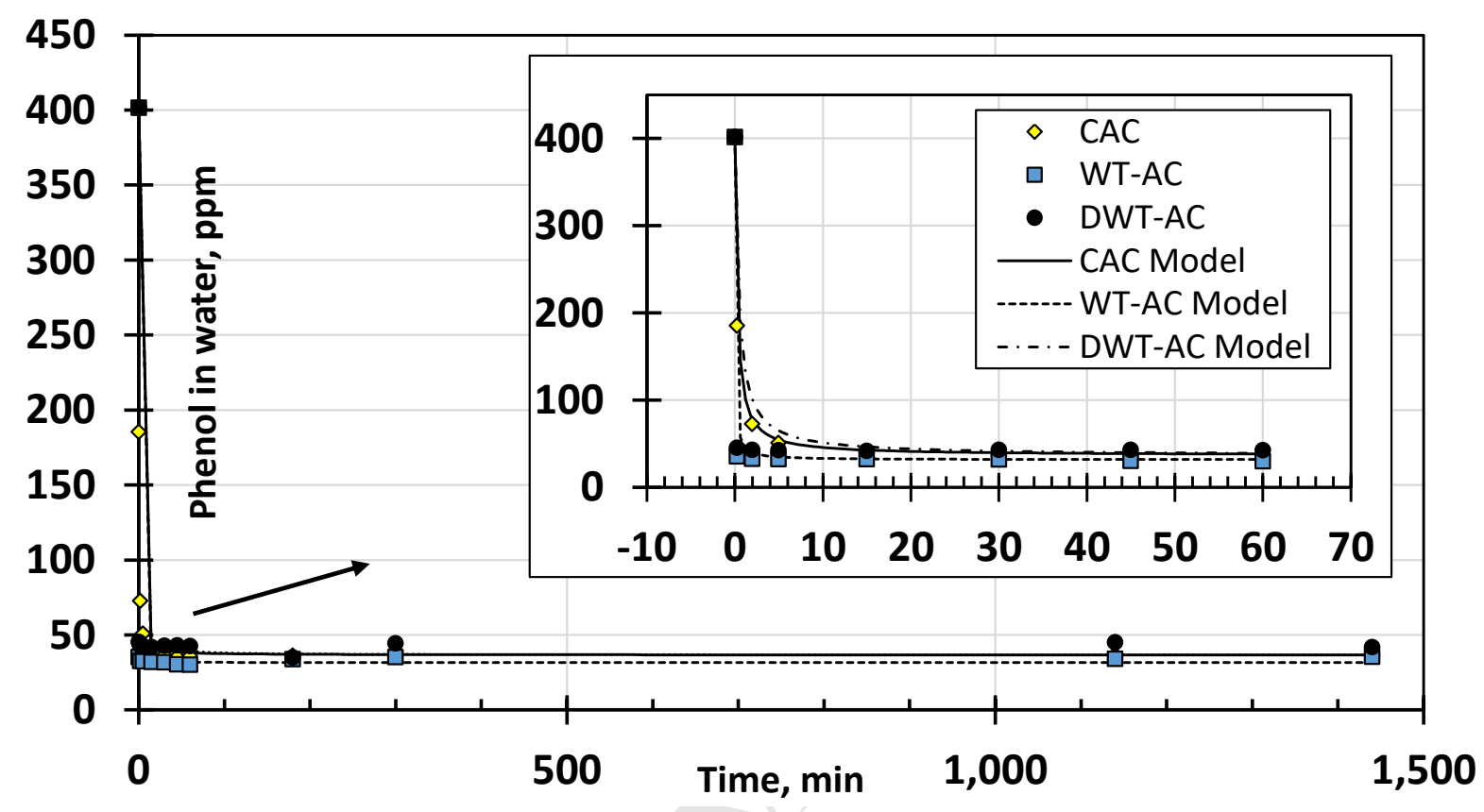

Fig. 3 

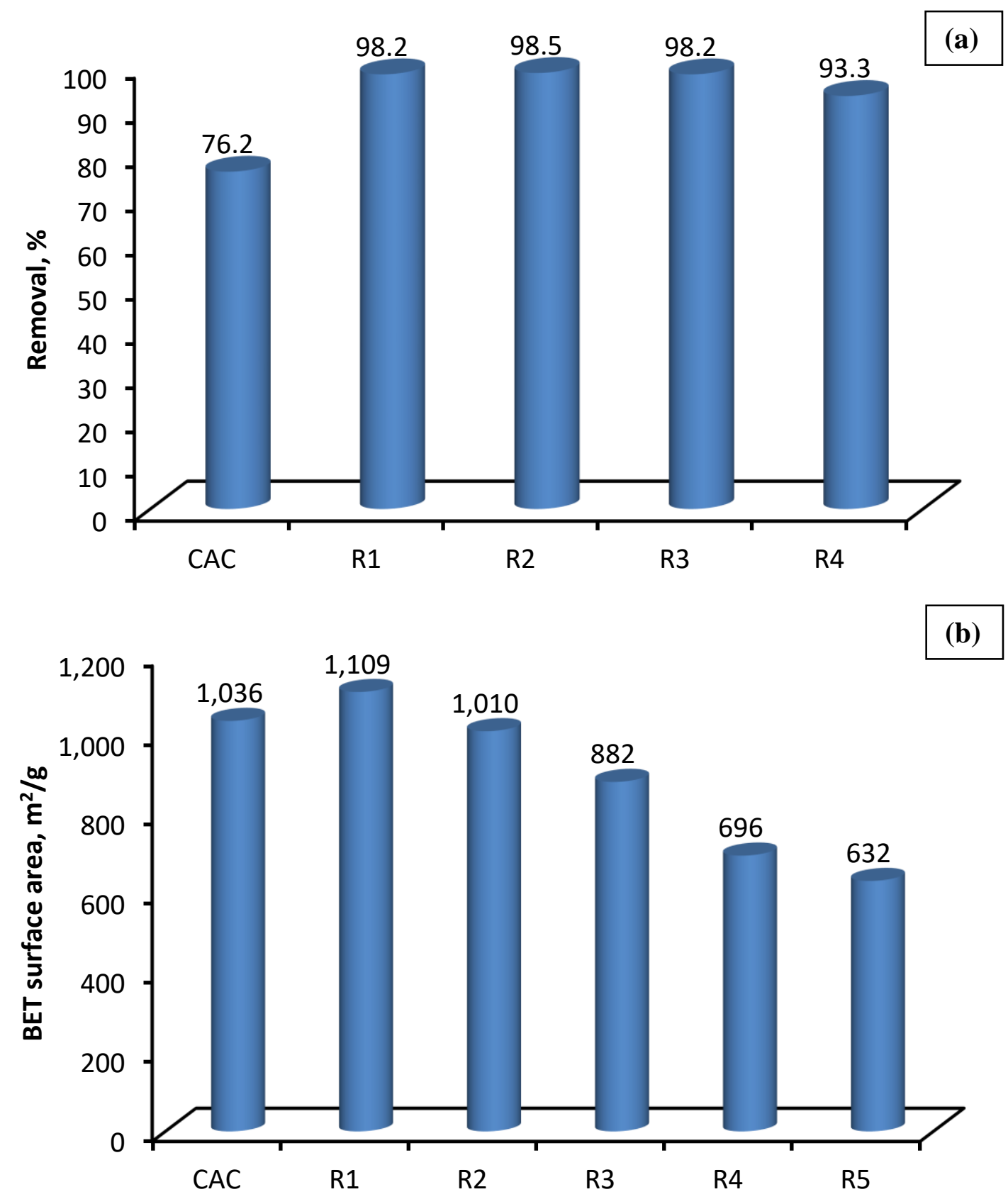

Fig. 4 

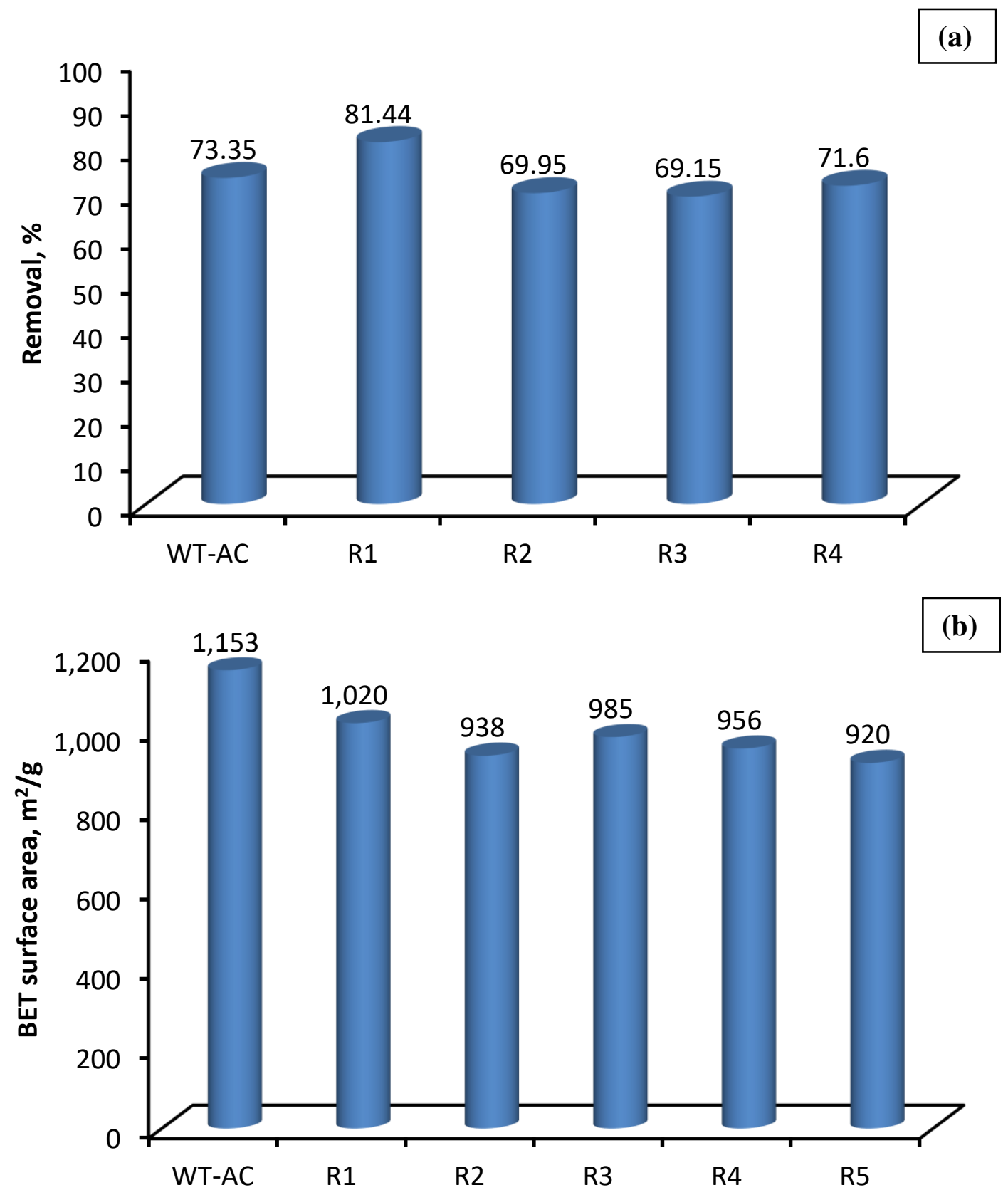

Fig. 5 


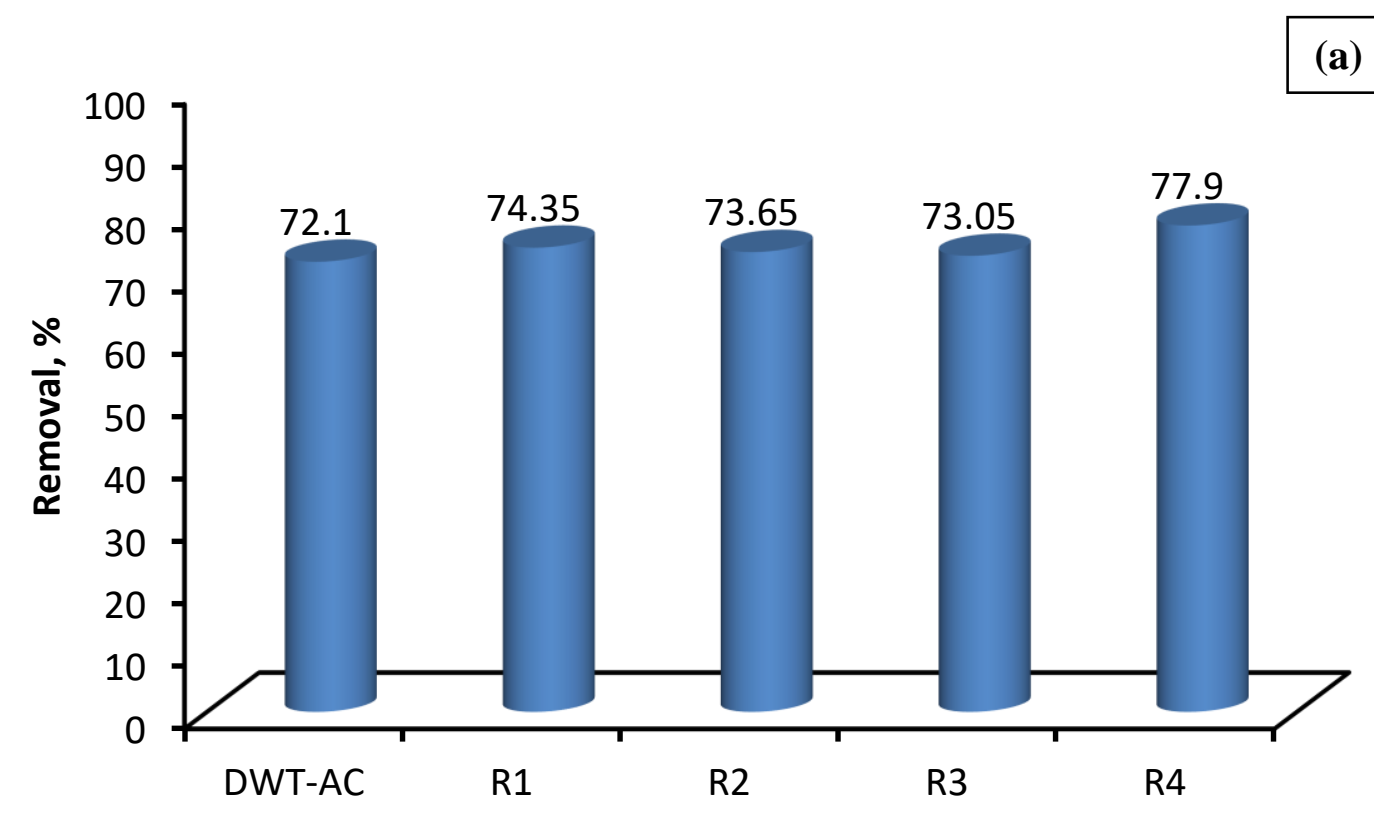

(a)

(b)

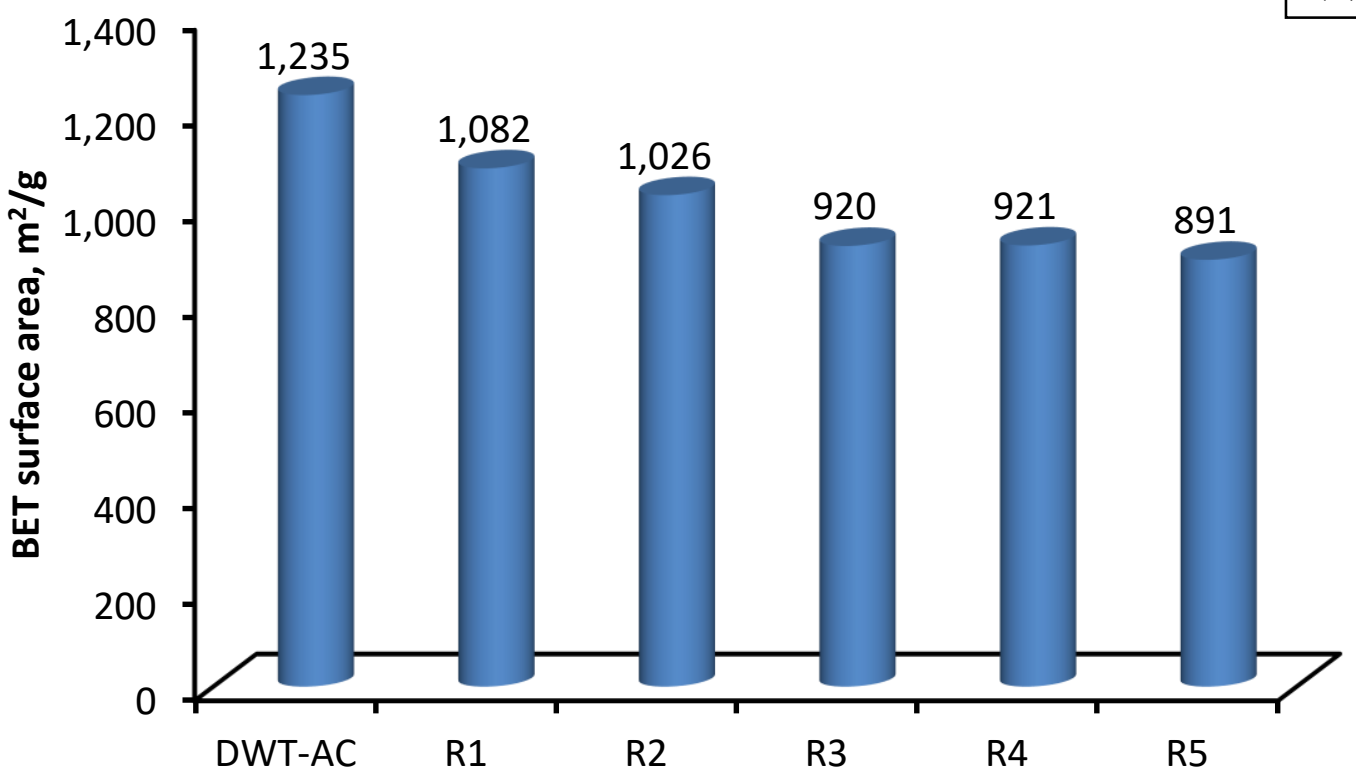

Fig 6. 

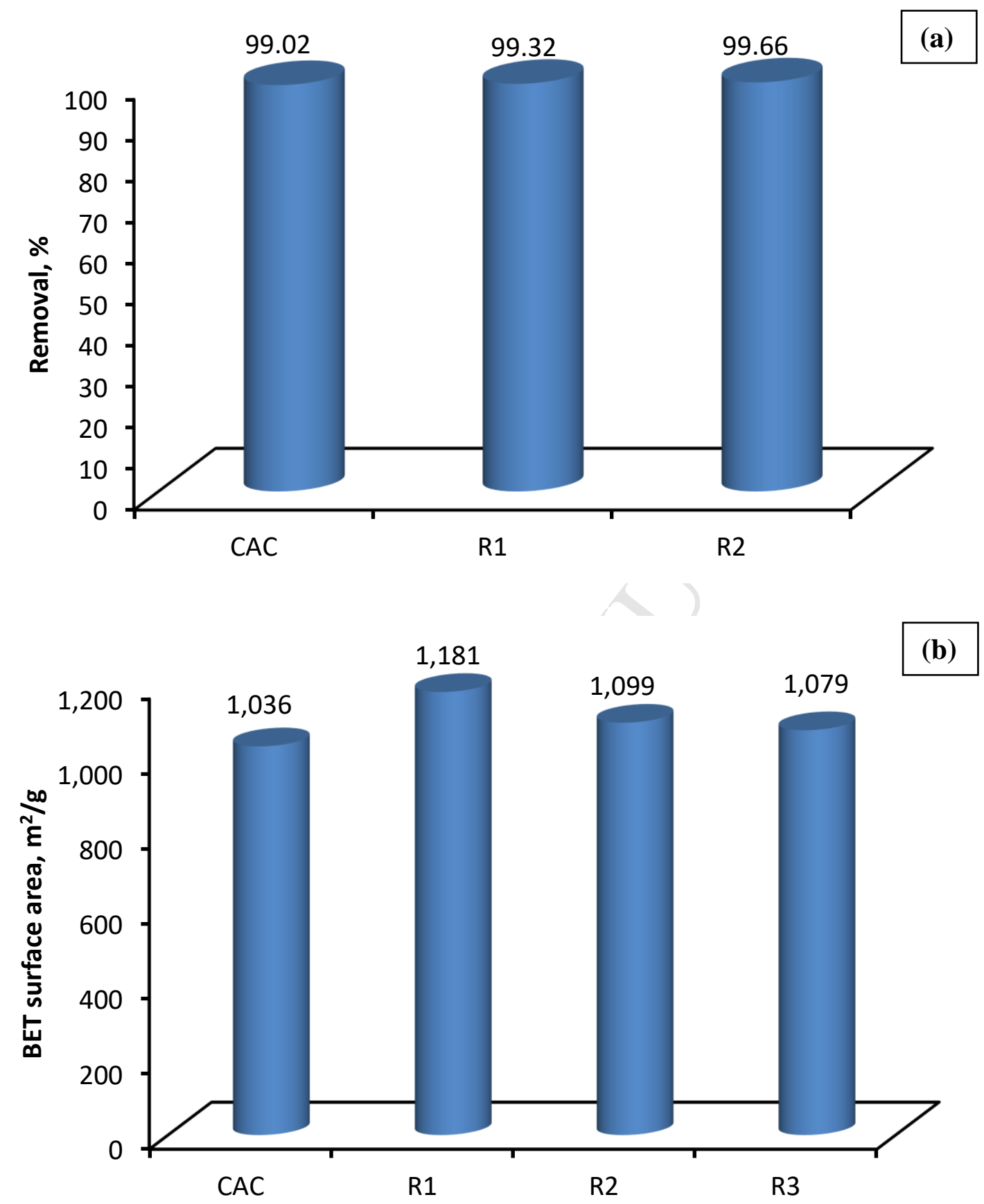

Fig.7 


\section{Highlights}

- The microwave irradiation based process is effective for regeneration and reuse

- Activated carbon was synthesised with phosphoric acid and using microwave energy

- Adsorbent capacity maintained through multiple adsorption/regeneration cycles

- Surface area and pore volume were altered by regeneration cycles

- Demineralisation significantly improved the removal capacity of the carbons 